\title{
Influence of Cationic Polyelectrolytes on Reactions of 2,4-Dinitrofluorobenzene with Amino Acids and Peptides
}

\author{
Toshio Ueda and Susumu Harada \\ Research Laboratory for Chemical Fibers, \\ Nitto Boseki Co., Ltd., Koriyama, Fukushima, Japan. \\ Norio IsE \\ Department of Polymer Chemistry, \\ Kyoto University, Sakyo-ku, Kyoto, Japan. \\ (Received December 3, 1973)
}

\begin{abstract}
Aromatic nucleophilic substitution reactions of 2,4-dinitrofluorobenzene with amino acids and peptides were accelerated in the presence of terpolymers of dimethyldiallylammonium chloride, methyldodecylbenzyldiallylammonium chloride, and sulfur dioxide. The higher the valency of the amino acids and the more hydrophobic the polycations, the larger the acceleration. As was the case for other reaction systems, the acceleration was due to a decrease in the enthalpy of activation.

KEY WORDS 2,4-Dinitrofluorobenzene / Amino Acids / Dimethyldiallylammonium Chloride-Methyldodecylbenzyldiallylammonium Chloride-Sulfur Dioxide Terpolymers / Cationic Polyelectrolytes / Polyelectrolyte Acceleration / Enthalpy of Activation /
\end{abstract}

It has been found that polyelectrolyte addition causes either large acceleration or large deceleration for a variety of interionic reactions. ${ }^{1}$ In a previous paper $^{2}$ the influence of polycations on an $S_{N} A r$ reaction of 2,4-dinitrochlorobenzene with $\mathrm{OH}^{-}$were investigated; it was found that the polycations having a long alkyl group (dodecyl) in the side chain accelerated this reaction noticeably. In order to understand the polyelectrolyte influence on chemical reactions in general, we extend our study to another ionmolecule reaction in the present paper. The reaction studied was an aromatic nuclophilic substitution reaction of 2,4-dinitrofluorobenzene (DNFB) with an amino acid or peptide.

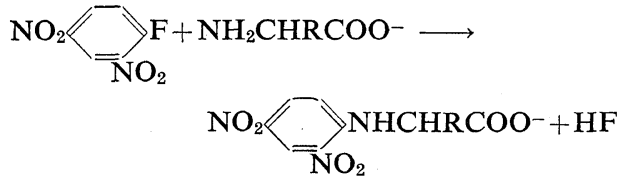

This reaction is used for the determination of the amino group at the end of a peptide chain. ${ }^{3}$ Bunton, et al., found that cetyltrimethylammoni- um bromide, a cationic surfactant, accelerated the reaction of DNFB with glycine, diglycine, and triglycine. ${ }^{4}$ Besides these amino acids and peptides, we studied L-serine, L- $\beta$-phenyl- $\alpha$ alanine, L-glutamic acid, and L-aspartic acid.

\section{EXPERIMENTAL}

\section{Materials}

Amino Acids and Peptides. Glycine, L-serine, L-phenylalanine, L-glutamic acid, L-aspartic acid, diglycine, and triglycine were guaranteed reagent grade commercial samples and were used without further purification. Before use, the amino acids and the peptides were dissolved in water and neutralized with $\mathrm{NaOH}$.

DNFB was of the G. R. grade and was used without further purification. The polycations used were an alternative copolymer of dimethyldiallylammonium chloride and $\mathrm{SO}_{2}(\mathrm{DM})$, that of methylbenzyldiallylammonium chloride and $\mathrm{SO}_{2}(\mathrm{MBZ})$, and four terpolymers of dimethyldiallylammonium chloride, methyldodecylbenzyldiallylammonium chloride, and $\mathrm{SO}_{2}(\mathrm{Dod})$ with 
varying monomer ratios. The syntheses of the polymers were described elesewhere. ${ }^{2,5,6}$ The polymers were purified by dialysis against pure water for ten days, using a cellophane membrane. For the monomer ratios of DM-Dod (I-IV), the previous paper ${ }^{2}$ should be referred.

\section{Kinetics}

The reactions were carried out in water and $\mathrm{pH}$ was controlled using carbonate buffers (Table I). The $\mathrm{pH}$ values were determined in such a way that (i) the amino group was present in solution as an undissociated form and (ii) the side reaction of DNFB with $\mathrm{OH}^{-}$was prevented.

The reaction rate was measured by following the appearance of the products spectrophotometrically, using a Shimazu spectrophotometer (SV-50A). The wavelengths used were $362 \mathrm{~nm}$ for glycine, serine, phenylalanine, aspartic acid, and glutamic acid, and $355 \mathrm{~nm}$ for diglycine and triglycine. The second-order rate constant was calculated graphically using the second-order rate equation. Control experiments showed that the contribution of the side reaction of DNFB with $\mathrm{OH}^{-}$to the over-all rate was smaller than $5 \%$.

\section{RESULTS AND DISCUSSION}

In Table $I$ are given the rate constants at $21^{\circ} \mathrm{C}$ of the reaction of DNFB with amino acids or peptides. It is seen that the higher the $\mathrm{p} K_{\mathrm{a}}$, the larger the rate constant, except for phenylalanine. In the present reaction, the reactivity of the reagent (or the nucleophilicity) is observed to be parallel to the basicity of the amino group, as was pointed out earlier by Jencks, et al. ${ }^{7}$

The effect of polycations on the rate constant

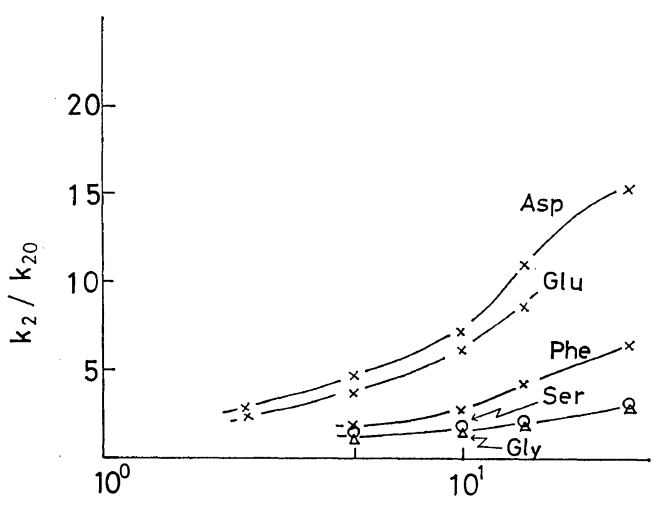

polyelectrolyte conen. $\times 10^{3}$ (monomole/l)

Figure 1. Influence of DM-Dod I on the reaction of DNFB with some amino acids and peptides at $21^{\circ} \mathrm{C}: \quad[\mathrm{DNFB}]=4.91 \times 10^{-5} \mathrm{M}$; [amino acid] $=$ $10^{-2} M$.

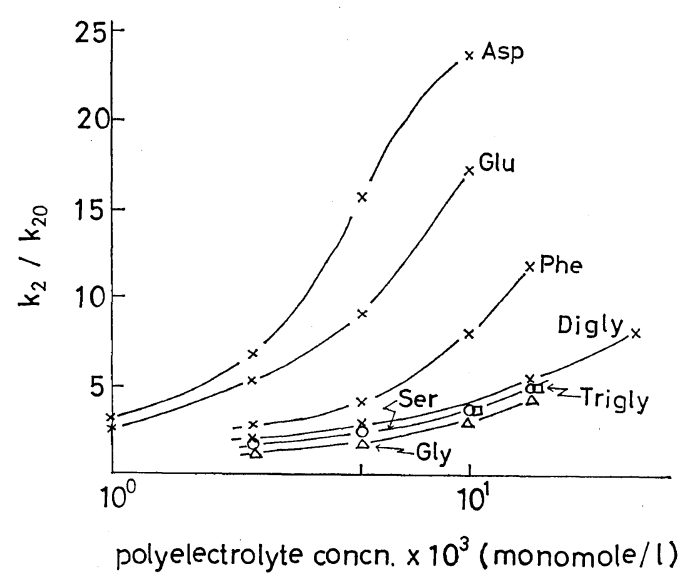

Figure 2. Influence of DM-Dod II on the reaction of DNFB with amino acids and peptides at $21^{\circ} \mathrm{C}$ : [DNFB] $=4.91 \times 10^{-5} \mathrm{M}$; [amino acid] $=10^{-2} \mathrm{M}$.

Table I. Reaction conditions of DNFB with amino acids and rate constants at $21^{\circ} \mathrm{C}^{\text {a }}$

\begin{tabular}{lccccc}
\hline \multirow{2}{*}{ Amino acid } & $\mathrm{pH}$ & \multicolumn{2}{c}{ Buffer } & & \multirow{2}{*}{$K_{\mathrm{aNH}_{2}}$} \\
\cline { 3 - 4 } & & $\mathrm{Na}_{2} \mathrm{CO}_{3}, M$ & $\mathrm{NaHCO}_{3} M$ & & \\
\hline Glycine & 10.5 & $12 \times 10^{-3}$ & $3.0 \times 10^{-3}$ & 9.78 & 1.7 \\
L- $\beta$-Phenylalanine & 10.2 & 7.5 & 7.5 & 9.12 & 1.1 \\
L-Glutamic acid & 10.5 & 12 & 3 & 9.67 & 0.91 \\
L-Aspartic acid & 10.5 & 12 & 3 & 9.62 & 0.89 \\
L-Serine & 10.2 & 7.5 & 7.5 & 9.15 & 0.46 \\
Diglycine & 9.5 & 3 & 12 & 8.25 & 0.17 \\
Triglycine & 9.5 & 3 & 12 & 8.09 & 0.16 \\
\hline
\end{tabular}

a $[$ amino acid $]=10^{-2} M,[\mathrm{DNFB}]=4.91 \times 10^{-5} M$. 


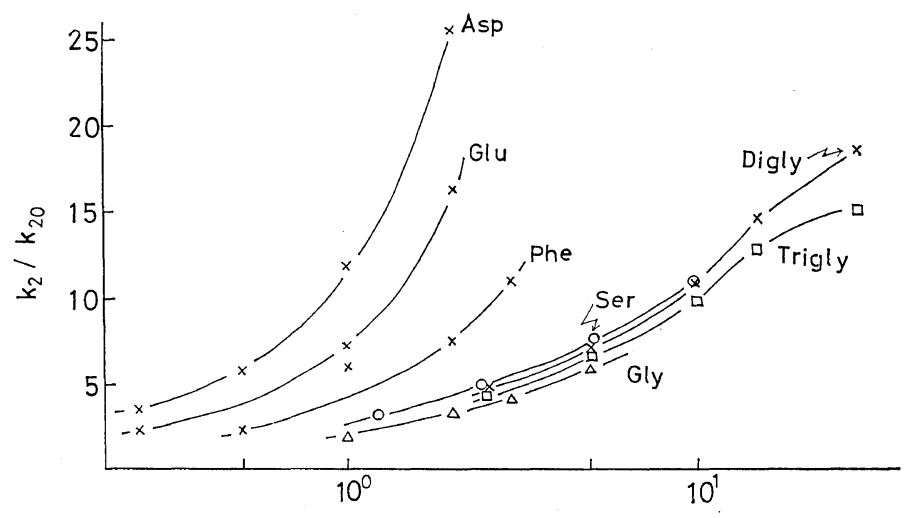

polyelectrolyte concn. $\times 10^{3}$ (monomole / I)

Figure 3. Influence of DM-Dod III on the reaction of DNFB with amino acids and peptides at $21^{\circ} \mathrm{C}:[\mathrm{DNFB}]=4.91 \times 10^{-5} \mathrm{M}$; [amino acid] $=10^{-2} \mathrm{M}$.

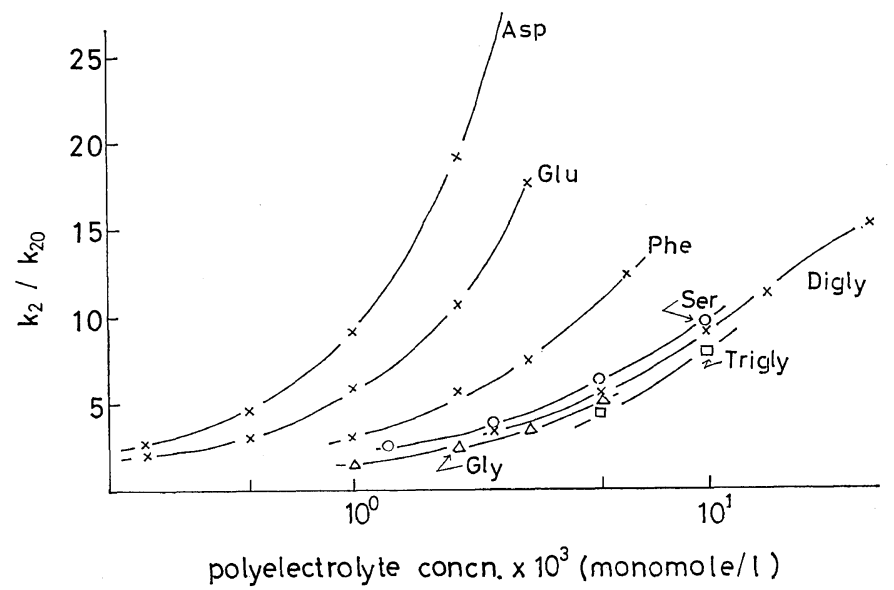

Figure 4. Influence of DM-Dod IV on the reaction of DNFB with amino acids and peptides at $21^{\circ} \mathrm{C}:[\mathrm{DNFB}]=4.91 \times 10^{-5} \mathrm{M} ;$ [ amino acid] $=10^{-2} M$.

$\left(k_{2}, k_{20}\right.$ : The second-order rate constants in the presence and absence of the polyelectrolytes) with glycine, L-serine, L-phenylalanine, L-glutamic acid, L-aspartic acid, diglycine, and triglycine are summarized in Figures $1-4$. The terpolymers accelerated the reaction and the degree of the acceleration increased with increasing Dod content. Though the data are not shown in the figures, we note that DM (containing no dodecylbenzylgroup) had very little influence on the reaction rate and MBZ (containing no dodecyl group) enhanced it only slightly. Such a tendency is in accord with those for the $S_{N} A r$ reaction of 2,4-dinitrochlorobenzene with $\mathrm{OH}^{-}{ }^{2}$ Rate- enhancing effects increased with increasing hydrophobicity of the polycations, indicating a hydrophobic interaction between the polycation and DNFB. As is seen from the figures, the acceleration became larger in the following order.

Amino acid; aspartic acid $>$ glutamic acid $>$ phenylalanine $>$ serine $\simeq$ glycine

Peptide; $\quad$ glycine $\simeq$ diglycine $\simeq$ triglycine.

Here attention should be paid to the number of electric charges on the amino acids or peptides. Since the carboxyl group of the amino acids or the peptides is completely dissociated under the reaction conditions, aspartic acid and glutamic 
acid are in the form of divalent anions, and phenylalanine, serine, and glycine are monovalent. The larger rate-enhancing effects for aspartic acid and glutamic acid may be attributed to their higher valency. This is in accord with the previous result that the acceleration effect of polyelectrolytes increased with increasing valency of ionic reactants for interionic reactions. ${ }^{1,8}$

Among the three monovalent amino acids, phenylalanine was accelerated more than glycine and serine. The hydrophobic interactions between the phenyl group of phenylalanine and the polycation, which also contains hydrophobic groups, may contribute to the rate enhancement. The observed acceleration is due to the stronger stabilization of the activated complex in the presence of polycations: in other words, it is

Table II. Thermodynamic quantities for the reaction of DNFB with diglycine at $25^{\circ} \mathrm{Ca}^{\mathrm{a}}$

\begin{tabular}{cccc}
\hline Polycation $^{\mathrm{b}}$ & $\begin{array}{c}\Delta H^{\neq}, \\
\mathrm{kcal} / \mathrm{mol}\end{array}$ & $\begin{array}{c}\Delta S^{\neq}, \\
\text {e.u. }\end{array}$ & $\begin{array}{c}\Delta G^{\neq}, \\
\mathrm{kcal} / \mathrm{mol}\end{array}$ \\
\hline DM-Dod I & 14.5 & -17 & 19.7 \\
II & 12.6 & -22 & 19.2 \\
III & 10.9 & -26 & 18.8 \\
IV & 10.6 & -26 & 18.3 \\
& 10.3 & -28 & 18.2
\end{tabular}

a $\mathrm{pH} 9.5,[\mathrm{DNFB}]=4.9 \times 10^{-5} \mathrm{M}$, [diglycine] $=10^{-2} \mathrm{M}$.

b at $1.5 \times 10^{-2} \mathrm{monomol} / \mathrm{l}$. essentially nothing else than the primary salt effect. $^{1}$

In Table II are shown the thermodynamic parameters of the reaction of DNFB and diglycine at $25^{\circ} \mathrm{C}$. The addition of the polycation lowered the enthalpy $\left(\Delta H^{\neq}\right)$and the entropy $\left(\Delta S^{*}\right)$ of activation, and the acceleration by the polycation is due to the lowering in $\Delta H^{\neq}$, as has been observed for many other reaction systems. $^{1}$

\section{REFERENCES}

1. For a convenient review on this topic, see the papers presented by $\mathrm{N}$. Ise at the Symposium on Polyelectrolytes, Pasadena, Troy, May 1973 or at the Advanced Studies Institute, New York, July 1973, to be published.

2. T. Ueda, S. Harada, and N. Ise, Polymer J., 6, 319 (1974).

3. F. Sanger, "Advances in Protein Chemistry," Vol. 7, Academic Press, New York, N. Y., 1952.

4. C. A. Bunton and L. Robinson, J. Amer. Chem. Soc., 93, 356 (1970).

5. S. Harada and K. Arai, Makromol. Chem., 107, 64 (1967).

6. T. Ueda, S. Harada, and N. Ise, Polymer J., 3, 476 (1972).

7. W. Jencks and J. Carrinolo, J. Amer. Chem. Soc., 82, 1778 (1960).

8. N. Ise and F. Matsui, ibid. 90, 4242 (1968). 